\title{
Effectiveness of a salt transport cascade in the renal medulla: computer simulations
}

\author{
PETER LORY \\ Mathematisches Institut der Technischen Universität München, D-8000 Munich 2, \\ Federal Republic of Germany
}

LORY, PETER. Effectiveness of a salt transport cascade in the renal medulla: computer simulations. Am. J. Physiol. 252 (Renal Fluid Electrolyte Physiol. 21): F1095-F1102, 1987.-Based on morphological observations, it has been concluded that the upper parts of the long descending limbs of Henle's loops should be able to secrete salts into the tubular fluid (Kriz, W. Federation Proc. 42: 2379-2385, 1983). In the same article, a hypothesis is given depicting how this active transport in concert with certain characteristics of the medullary architecture might produce a transport cascade toward the papillary tip, thus supporting the accumulation of salts in this region. The effectiveness of the proposed mechanism can be judged by a mathematical model only. The computer simulations of the present study demonstrate that this mechanism indeed leads to an increase of the concentrating capability of the renal countercurrent system.

mathematical model; active salt transport; medullary architecture

BASED ON MORPHOLOGICAL observations in some species, it has been concluded $(21,23)$ that the upper parts of the long descending limbs of Henle's loops should be able to secrete salts into the tubular fluid. The experiments of Ernst and Schreiber (7), who have demonstrated membrane-bound $\mathrm{Na}^{+}-\mathrm{K}^{+}$-ATPase activity of the epithelium in the rat, support this assumption. However, it has so far escaped verification by isolated tubule perfusion techniques.

It is characteristic for the renal inner medulla to taper from a broad basis to a very thin papilla $(20,21)$. The long loops of Henle reach different levels in the inner medulla and decrease rapidly in number from the base to the tip of the papilla. Kriz $(21,22)$ gives a hypothesis concerning how these characteristics of the medullary architecture in concert with the above-mentioned active transport might produce a transport cascade toward the papillary tip, thus supporting the accumulation of salts in this region (see MATHEMATICAL MODEL). The effectiveness of the proposed mechanism can be judged by a mathematical model only. The computer simulations of the present study test the hypothesis with a new differential equation model of the renal tubular system.

\section{MATHEMATICAL MODEL}

The mathematical model is a successor of previously published kidney models $(11,26-28,34)$. Like these models, it describes local mass balance for water, salt, and urea in the single tubules by differential equations:

$$
\begin{array}{ll}
\mathrm{F}_{i \mathrm{v}}^{\prime}(s)=-2 \pi R_{i} \times \mathrm{J}_{i \mathrm{v}}(s) & \prime=\mathrm{d} / \mathrm{d} s \\
\mathrm{~F}_{i \mathrm{I}}^{\prime}(s)=-2 \pi R_{i} \times \mathrm{J}_{i \mathrm{I}}(s) & \mathrm{I}=1 \text { (salt), } 2 \text { (urea) }
\end{array}
$$

where $i=1$, descending limb of Henle's loop (DLH); $i=2$, ascending limb of Henle's loop (ALH); $i=3$, distal tubule (DT); $i=4$, collecting duct (CD); $s$, distance into the medulla from the corticomedullary border; $R_{i}$, radius of tubule $i ; \mathrm{F}_{i v}$, volume flow rate in tubule $i ; \mathrm{F}_{i \mathrm{I}}$, flow rate of solute I in tubule $i$.

The transmural fluxes, $J_{i v}$ and $J_{i 1}$, obey the laws of irreversible thermodynamics (16)

$$
\begin{aligned}
J_{i \mathrm{v}}= & \mathrm{L}_{\mathrm{p}_{i}} \times\left[1.82 \sigma_{i 1}\left(\mathrm{C}_{61}-\mathrm{C}_{i 1}\right)+\sigma_{i 2}\left(\mathrm{C}_{62}-\mathrm{C}_{i 2}\right)\right] \\
J_{i \mathrm{I}}= & P_{i \mathrm{I}} \times\left(\mathrm{C}_{i \mathrm{I}}-\mathrm{C}_{6 \mathrm{I}}\right)+\left(1-\sigma_{i \mathrm{I}}\right) \times J_{i \mathrm{v}} \\
& \times\left(\mathrm{C}_{i \mathrm{I}}+\mathrm{C}_{6 \mathrm{I}}\right) / 2+\mathrm{T}_{i \mathrm{I}}
\end{aligned}
$$

where $L_{p_{i}}$ is hydraulic water conductivity of the wall of tubule $i ; P_{i 1}$, permeability of the wall of tubule $i$ for solute I; $\sigma_{i 1}$, reflection coefficient; $\mathrm{C}_{i \mathrm{I}}$, concentration of solute I in tubule $i(i=1, \cdots, 4) ; \mathrm{C}_{6 \mathrm{I}}$, concentration of solute I in the central core (33). In the tubules, axial diffusion may be neglected $(8,28)$, so $\mathrm{C}_{i \mathrm{I}}=\mathrm{F}_{i \mathrm{I}} / \mathrm{F}_{i \mathrm{v}}$ for $i=1, \cdots$, 4 .

The active transport, $T_{i \mathrm{il}}$, is assumed to obey MichaelisMenten kinetics, namely

$$
\mathrm{T}_{i \mathrm{I}}=V_{\mathrm{m}_{i \mathrm{I}}} \times \overline{\mathrm{C}}_{i \mathrm{I}} /\left(K_{\mathrm{m}_{i \mathrm{I}}}+\overline{\mathrm{C}}_{i \mathrm{I}}\right)
$$

where $\bar{C}_{i \mathrm{I}}=\mathrm{C}_{i \mathrm{I}}$ if $\mathrm{T}_{i \mathrm{I}}$ is directed outwards, and $\overline{\mathrm{C}}_{i \mathrm{I}}=\mathrm{C}_{6 \mathrm{I}}$ if $\mathrm{T}_{i \mathrm{I}}$ is directed inwards. $V_{\mathrm{m}_{\mathrm{I}}}$ is the maximum rate of transport, and $K_{\mathrm{m}_{11}}$ is the Michaelis constant. In the model, only salt is transported actively. This active transport occurs in the outer medullary sections of the ascending limbs and in the distal tubules. There it is directed outward. Furthermore, the active transport occurs in certain parts of the descending limbs (see below), there it is directed inward.

Table 1 gives the thermodynamic parameters. As far as possible values are those measured directly in isolated perfused tubules.

For the hydraulic conductivity in the inner medullary $\mathrm{CD}$, the value of Morgan and Berliner (29) was preferred to the (lower) value of Rocha and Kokko (31). If the latter value is used in the model, not enough water is osmotically extracted from the CD fluid when it flows 
TABLE 1. Thermodynamic parameters

\begin{tabular}{|c|c|c|c|c|c|c|c|}
\hline & \multirow{2}{*}{ DLH } & \multicolumn{2}{|c|}{$\mathrm{ALH}$} & \multirow{2}{*}{ DT } & \multicolumn{2}{|c|}{$\mathrm{CD}$} & \multirow{2}{*}{ Pelvis } \\
\hline & & IM & OM & & $\mathrm{OM}$ & IM & \\
\hline$L_{\mathrm{p}}, \mathrm{nl} \cdot \mathrm{cm}^{-2} \cdot \min ^{-1}(\operatorname{mosmol} / 1)^{-1}$ & $\begin{array}{l}247 \\
(18)\end{array}$ & $\begin{array}{c}0 \\
(12)\end{array}$ & $\begin{array}{c}0 \\
(30)\end{array}$ & $\begin{array}{l}48.4 \\
(2)\end{array}$ & $\begin{array}{l}48.4 \\
(2)\end{array}$ & $\begin{array}{c}30 \\
(29)\end{array}$ & 0 \\
\hline$P_{\text {salt }}, 10^{-5} \mathrm{~cm} / \mathrm{s}$ & $\begin{array}{l}0.17 \\
(1)\end{array}$ & $\begin{array}{l}25 \\
(12)\end{array}$ & $\begin{array}{l}6.27 \\
(30)\end{array}$ & $\begin{array}{c}0.8 \\
(28)\end{array}$ & 0 & 0 & 0 \\
\hline$P_{\text {urea, }} 10^{-5} \mathrm{~cm} / \mathrm{s}$ & $\begin{array}{r}0^{*} \\
(19)\end{array}$ & $\begin{array}{l}6.7 \\
(12)\end{array}$ & $\begin{array}{c}0 \\
(31)\end{array}$ & Lin trans $\dagger$ & $\begin{array}{l}0.097 \\
(4)\end{array}$ & $\begin{array}{l}2.4 \\
(31)\end{array}$ & 15 \\
\hline$\sigma_{\text {salt }}$ & $\begin{array}{l}0.96 \\
(18)\end{array}$ & & & 1 & 1 & 1 & \\
\hline$\sigma_{\text {urea }}$ & $\begin{array}{c}1^{*} \\
(19)\end{array}$ & & & 1 & $\begin{array}{c}1 \\
(32)\end{array}$ & $\begin{array}{l}0.74 \\
(31)\end{array}$ & \\
\hline
\end{tabular}

Numbers in parentheses indicate references. If no reference is given explicitly see text and Ref. 26. DLH, descending limb of Henle's loop; ALH, ascending limb of Henle's loop; DT, distal tubule; IM, inner medulla; OM, outer medulla. CD, collecting duct; $L_{p}$, hydraulic water conductivity; $P_{\text {ealt, }}$, permeability to salt; $P_{\text {uroa }}$, permeability to urea; $\sigma_{\text {aalt }}$, reflection coefficient for salt; $\sigma_{\text {urea }}$, reflection coefficient for urea. ${ }^{*}$ Slightly idealized. + Linear transition from 0 to 1 (consistent with Refs. 5 and 35 ).

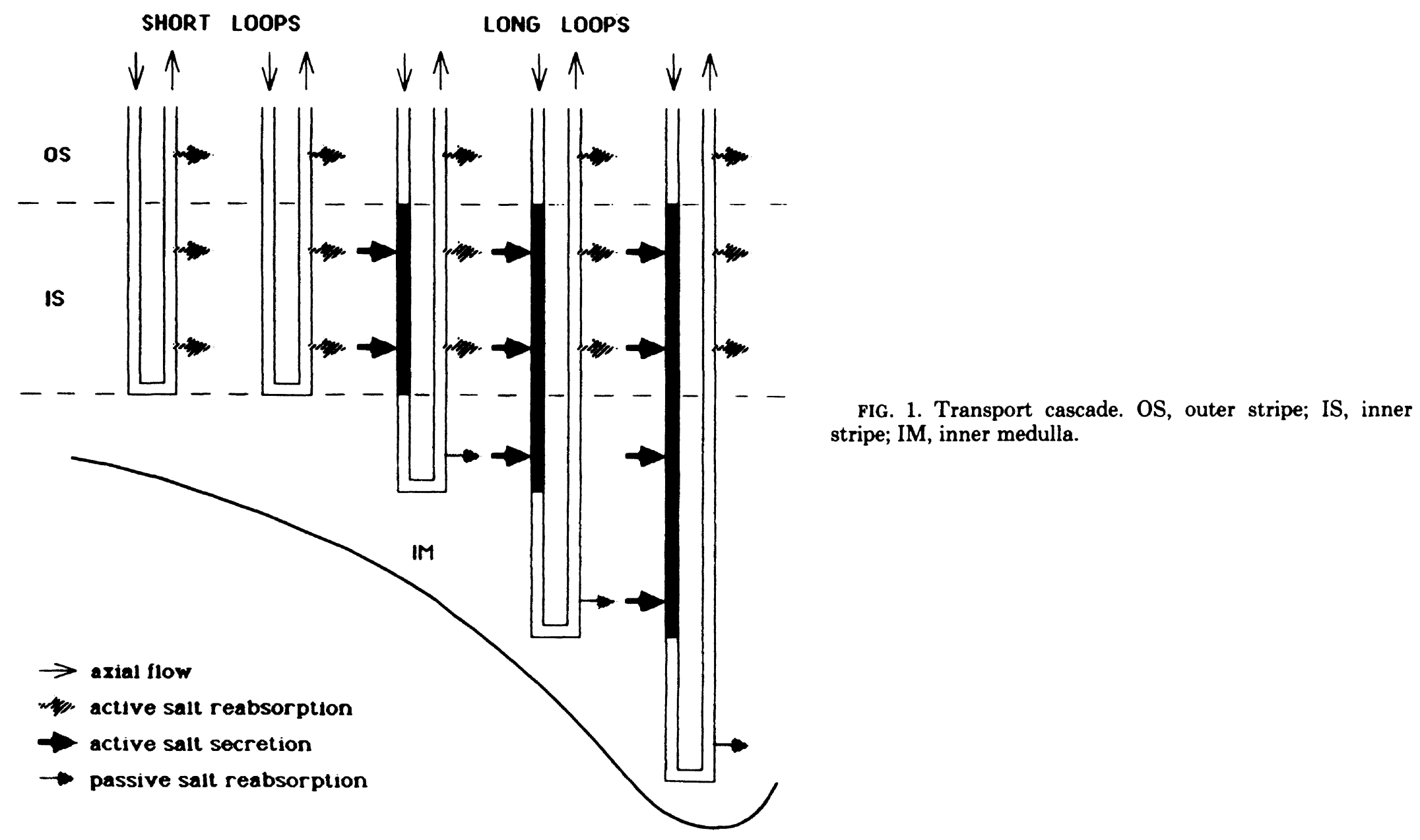

down the medulla, and $\mathrm{CD}$ and surrounding central core do not reach nearly osmotic equilibrium. This would be inconsistent with classic experimental findings (9).

For the CD parameters a linear transition zone between outer and inner medulla was assumed in $4.5 \leq s \leq 7.5$. The ALH parameters, however, change abruptly at the outer-inner medullary junction.

The DT parameters meet the requirement that late distal fluid is isosmotic (9). Additional arguments for the chosen set of thermodynamic parameters, especially those for the pelvis, may be found in the work done by Lory et al. (26).

The length of the medulla is assumed to be $10.5 \mathrm{~mm}$ (outer medulla, $4.5 \mathrm{~mm}$; inner medulla, $6 \mathrm{~mm}$ ). The medullary architecture of the tubular system is modeled very carefully and considers recent experimental morphological results $(3,20,21)$. The number of collecting ducts remains constant in the outer medulla. On entering the inner medulla, however, they fuse together in a dichotomous manner on eight successive levels. Therefore, the inner medulla of the model is subdivided into eight equal parts: $c_{1}=4.5$ (outer-inner medullary junction), $c_{2}=5.25, \cdots, c_{8}=9.75, c_{9}=10.5$ (papillary tip). In each $s$-interval $c_{k-1}<s \leq c_{k}, 2^{9-k}$ collecting ducts are present $(k=2, \cdots, 9)$. In the outer medulla, 256 .

As six nephrons drain into one CD, 1,536 loops of Henle eventually merge into one CD. Consequently, this number of loops is modeled. Two-thirds of these loops $(1,024)$ are short loops, which reach from the corticomedullary border $(s=0)$ to the outer-inner medullary 
TABLE 2. Simulated tubule fluid-to-plasma salt in loops of Henle during absence $\left(S_{0}\right)$ and during presence $\left(S_{1}\right)$ of active salt transport into descending limbs

\begin{tabular}{|c|c|c|c|c|c|c|c|c|c|c|c|c|}
\hline \multirow{3}{*}{$s$} & \multicolumn{2}{|c|}{ Short Loop } & \multicolumn{10}{|c|}{ Long Loop of Group j } \\
\hline & \multirow{2}{*}{ DLH } & \multirow{2}{*}{ ALH } & \multicolumn{2}{|c|}{$\mathrm{j}=2$} & \multicolumn{2}{|c|}{$j=3$} & \multicolumn{2}{|c|}{$\mathrm{j}=4$} & \multicolumn{2}{|c|}{$\mathrm{j}=5$} & \multicolumn{2}{|c|}{$j=6$} \\
\hline & & & $\mathrm{DLH}$ & $\overline{A L H}$ & $\overline{\mathrm{DLH}}$ & $\overline{\mathrm{ALH}}$ & $\overline{\mathrm{DLH}}$ & $\overline{\mathrm{ALH}}$ & $\overline{\mathrm{DLH}}$ & $\overline{\mathrm{ALH}}$ & $\overline{\mathrm{DLH}}$ & $\overline{\mathrm{ALH}}$ \\
\hline \multirow[t]{2}{*}{0.00} & 1.00 & 0.489 & 1.00 & 0.478 & 1.00 & 0.462 & 1.00 & 0.443 & 1.00 & 0.412 & 1.00 & 0.374 \\
\hline & 1.00 & 0.499 & 1.00 & 0.571 & 1.00 & 0.547 & 1.00 & 0.520 & 1.00 & 0.495 & 1.00 & 0.422 \\
\hline \multirow[t]{2}{*}{4.50} & 3.15 & 3.15 & 3.15 & 2.91 & 3.15 & 2.87 & 3.15 & 2.87 & 3.15 & 2.89 & 3.15 & 2.92 \\
\hline & 3.04 & 3.04 & 3.09 & 2.87 & 3.09 & 2.81 & 3.09 & 2.80 & 3.09 & 2.81 & 3.09 & 2.83 \\
\hline \multirow[t]{2}{*}{5.25} & & & 3.23 & 3.23 & 3.23 & 2.75 & 3.23 & 2.69 & 3.23 & 2.69 & 3.23 & 2.70 \\
\hline & & & 3.16 & 3.16 & 3.16 & 2.76 & 3.16 & 2.67 & 3.18 & 2.66 & 3.18 & 2.67 \\
\hline \multirow[t]{2}{*}{6.00} & & & & & 3.42 & 3.42 & 3.42 & 2.68 & 3.42 & 2.61 & 3.42 & 2.61 \\
\hline & & & & & 3.32 & 3.32 & 3.32 & 2.73 & 3.34 & 2.62 & 3.34 & 2.61 \\
\hline \multirow[t]{2}{*}{6.75} & & & & & & & 3.69 & 3.69 & 3.69 & 2.57 & 3.69 & 2.56 \\
\hline & & & & & & & 3.54 & 3.54 & 3.56 & 2.67 & 3.58 & 2.63 \\
\hline \multirow[t]{2}{*}{8.25} & & & & & & & & & 4.44 & 4.44 & 4.44 & 3.00 \\
\hline & & & & & & & & & 4.23 & 4.23 & 4.26 & 3.20 \\
\hline \multirow[t]{2}{*}{10.5} & & & & & & & & & & & 6.91 & 6.91 \\
\hline & & & & & & & & & & & 6.74 & 6.74 \\
\hline
\end{tabular}

In each pair, upper value refers to simulation $\mathrm{S}_{0}$, lower value refers to simulation $\mathrm{S}_{1}$. DLH, descending limb of Henle's loop; $A L H$, ascending limb of Henle's loop; $s$, distance into medulla from corticomedullary border.

TABLE 3. Simulated tubule fluid-to-plasma urea in loops of Henle during absence $\left(S_{0}\right)$ and during presence $\left(S_{1}\right)$ of active salt transport into descending limbs

\begin{tabular}{|c|c|c|c|c|c|c|c|c|c|c|c|c|}
\hline \multirow{2}{*}{$s$} & \multicolumn{2}{|c|}{ Short Loop } & \multicolumn{10}{|c|}{ Long Loop of Group $j$} \\
\hline & DLH & $\mathrm{ALH}$ & $\overline{\mathrm{DLH}}$ & $\overline{\mathrm{ALH}}$ & $\overline{\mathrm{DLH}}$ & $\overline{\mathrm{ALH}}$ & $\overline{\mathrm{DLH}}$ & $\overline{\mathrm{ALH}}$ & DLH & $\overline{\mathrm{ALH}}$ & $\overline{\mathrm{DLH}}$ & ALH \\
\hline 0.00 & 2.00 & 6.36 & 2.00 & 8.51 & 2.00 & 12.5 & 2.00 & 15.8 & 2.00 & 19.1 & 2.00 & 18.2 \\
\hline \multirow[t]{2}{*}{4.50} & 6.61 & 6.61 & 6.61 & 11.1 & 6.61 & 15.6 & 6.61 & 18.9 & 6.61 & 20.5 & 6.61 & 17.7 \\
\hline & 6.36 & 6.36 & 5.10 & 8.51 & 5.10 & 12.5 & 5.10 & 15.8 & 5.10 & 19.1 & 5.10 & 18.2 \\
\hline \multirow[t]{2}{*}{6.00} & & & & & 7.22 & 7.22 & 7.22 & 20.9 & 7.22 & 33.8 & 7.22 & 34.3 \\
\hline & & & & & 5.50 & 5.50 & 5.50 & 15.1 & 4.96 & 26.0 & 4.96 & 30.1 \\
\hline \multirow{2}{*}{6.75} & & & & & & & 7.85 & 7.85 & 7.85 & 35.8 & 7.85 & 41.3 \\
\hline & & & & & & & 5.91 & 5.91 & 5.30 & 24.9 & 5.06 & 33.7 \\
\hline \multirow[t]{2}{*}{8.25} & & & & & & & & & 9.59 & 9.59 & 9.59 & 54.1 \\
\hline & & & & & & & & & 6.38 & 6.38 & 5.53 & 38.1 \\
\hline 10.5 & & & & & & & & & & & 15.5 & 15.5 \\
\hline
\end{tabular}

In each pair, upper value refers to simulation $S_{0}$, lower value refers to simulation $S_{1}$. DLH, descending limb of Henle's loop; ALH, ascending limb of Henle's loop; $s$, distance into medulla from corticomedullary border.

TABLE 4. Simulated tubule fluid-to-plasma osmolarity in loops of Henle during absence $\left(S_{0}\right)$ and during presence $\left(S_{1}\right)$ of active salt transport into descending limbs

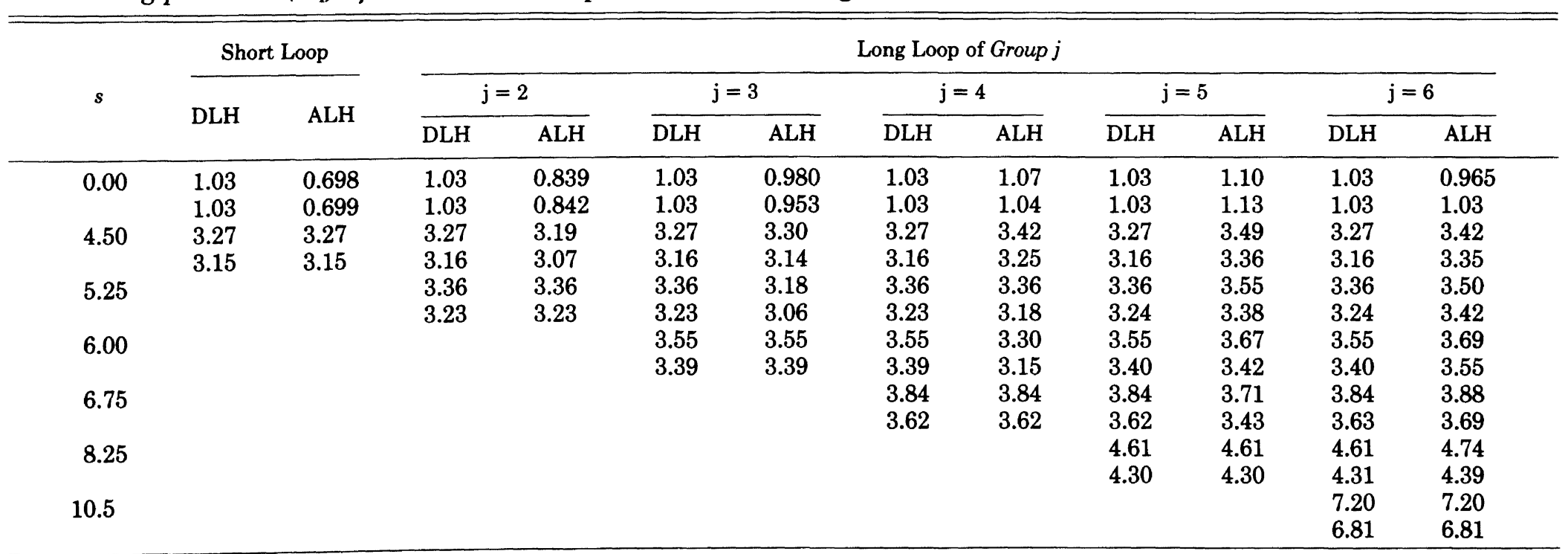

In each pair, upper value refers to simulation $S_{0}$, lower value refers to simulation $S_{1}$. DLH, descending limb of Henle's loop; ALH, ascending limb of Henle's loop; $s$, distance into medulla from corticomedullary border. 
TABLE 5. Simulated tubule fluid/plasma inulin in loops of Henle during absence $\left(S_{0}\right)$ and during presence $\left(S_{1}\right)$ of active salt transport into descending limbs

\begin{tabular}{|c|c|c|c|c|c|c|c|c|c|c|c|c|}
\hline \multirow{3}{*}{$s$} & \multicolumn{2}{|c|}{ Short Loop } & \multicolumn{10}{|c|}{ Long Loop of Group $j$} \\
\hline & \multirow{2}{*}{ DLH } & \multirow{2}{*}{ ALH } & \multicolumn{2}{|c|}{$\mathrm{j}=2$} & \multicolumn{2}{|c|}{$j=3$} & \multicolumn{2}{|c|}{$\mathrm{j}=4$} & \multicolumn{2}{|c|}{$j=5$} & \multicolumn{2}{|c|}{$j=6$} \\
\hline & & & DLH & ALH & DLH & ALH & DLH & ALH & DLH & ALH & DLH & ALH \\
\hline \multirow[t]{2}{*}{0.00} & 3.00 & 9.91 & 3.00 & 10.2 & 3.00 & 10.8 & 3.00 & 11.8 & 3.00 & 14.4 & 3.00 & 23.2 \\
\hline & 3.00 & 9.54 & 3.00 & 7.83 & 3.00 & 8.25 & 3.00 & 8.86 & 3.00 & 9.56 & 3.00 & 13.5 \\
\hline \multirow{2}{*}{4.50} & 9.91 & 9.91 & 9.91 & 10.2 & 9.91 & 10.8 & 9.91 & 11.8 & 9.91 & 14.4 & 9.91 & 23.2 \\
\hline & 9.54 & 9.54 & 7.65 & 7.83 & 7.65 & 8.25 & 7.65 & 8.86 & 7.65 & 9.56 & 7.65 & 13.5 \\
\hline \multirow[t]{2}{*}{5.25} & & & 10.2 & 10.2 & 10.2 & 10.8 & 10.2 & 11.8 & 10.2 & 14.4 & 10.2 & 23.2 \\
\hline & & & 7.83 & 7.83 & 7.83 & 8.25 & 7.83 & 8.86 & 7.43 & 9.56 & 7.43 & 13.5 \\
\hline \multirow[t]{2}{*}{6.00} & & & & & 10.8 & 10.8 & 10.8 & 11.8 & 10.8 & 14.4 & 10.8 & 23.2 \\
\hline & & & & & 8.25 & 8.25 & 8.25 & 8.86 & 7.43 & 9.56 & 7.43 & 13.5 \\
\hline \multirow[t]{2}{*}{6.75} & & & & & & & 11.8 & 11.8 & 11.8 & 14.4 & 11.8 & 23.2 \\
\hline & & & & & & & 8.86 & 8.86 & 7.96 & 9.56 & 7.60 & 13.5 \\
\hline \multirow[t]{2}{*}{8.25} & & & & & & & & & 14.4 & 14.4 & 14.4 & 23.2 \\
\hline & & & & & & & & & 9.56 & 9.56 & 8.30 & 13.5 \\
\hline \multirow{2}{*}{10.5} & & & & & & & & & & & 23.2 & 23.2 \\
\hline & & & & & & & & & & & 13.5 & 13.5 \\
\hline
\end{tabular}

In each pair, upper value refers to simulation $S_{0}$, lower value refers to simulation $S_{1}$. DLH, descending limb of Henle's loop; $A L H$, ascending limb of Henle's loop; $s$, distance into medulla from corticomedullary border.

junction $(s=4.5)$. This is group 1 of the loops. The 512 long loops are subdivided into groups $2-6$, which reach different levels of the inner medulla: group 2 (256 loops) reaches $s=5.25$; group 3 (128 loops) reaches $s=6.0$;

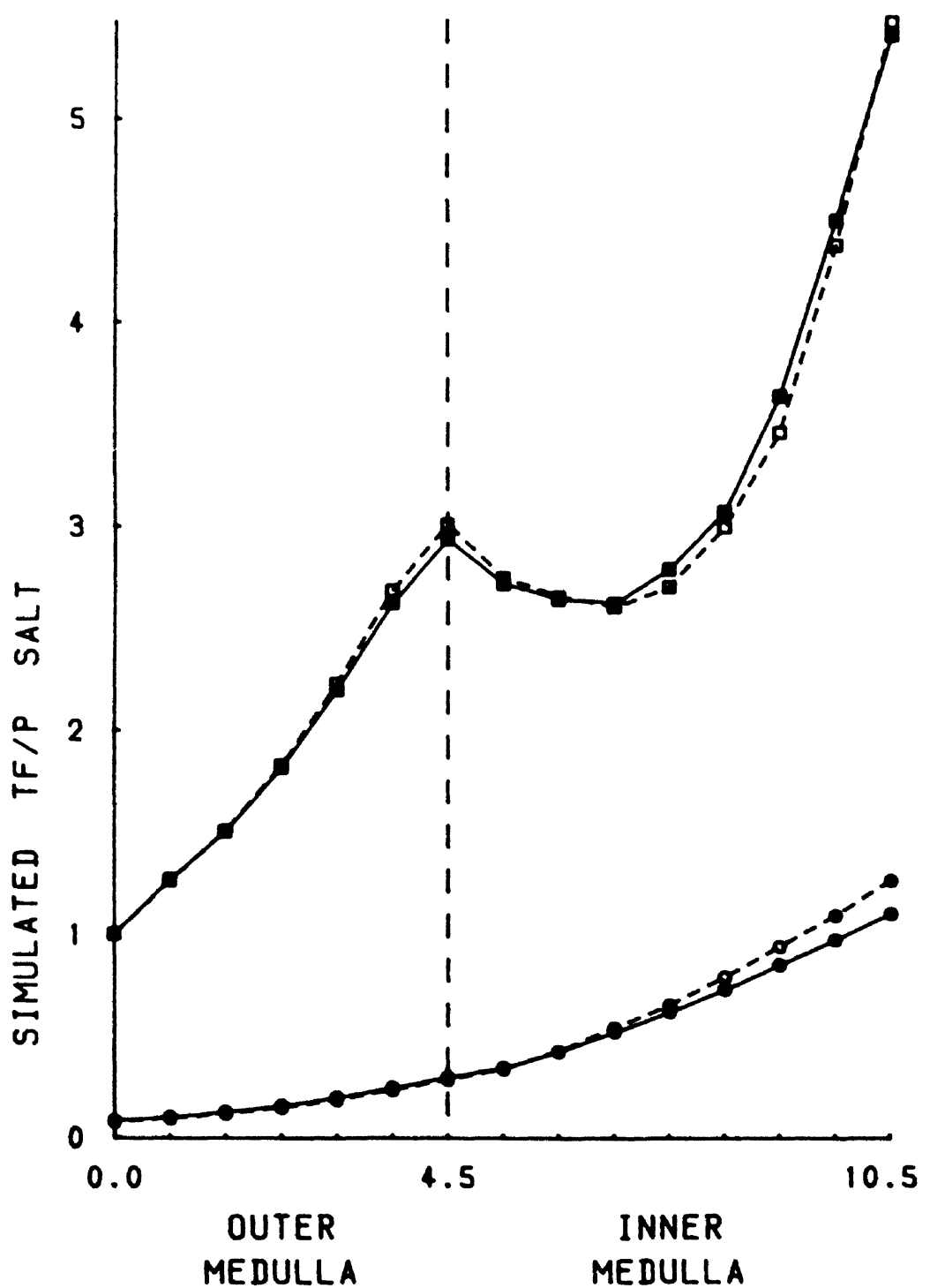

FIG. 2. Simulated salt concentration in collecting ducts (open circles, closed circles) and central core (open squares, closed squares). Open symbols, simulation $\mathrm{S}_{0}$; closed symbols, simulation $\mathrm{S}_{1}$. TF/P, tubule fluid-to-plasma. group 4 (64 loops) reaches $s=6.75$; group 5 (32 loops) reaches $s=8.25$; group 6 (32 loops) reaches $s=10.5$. So the number of loops decreases nearly exponentially in the inner medulla in agreement with the experimental

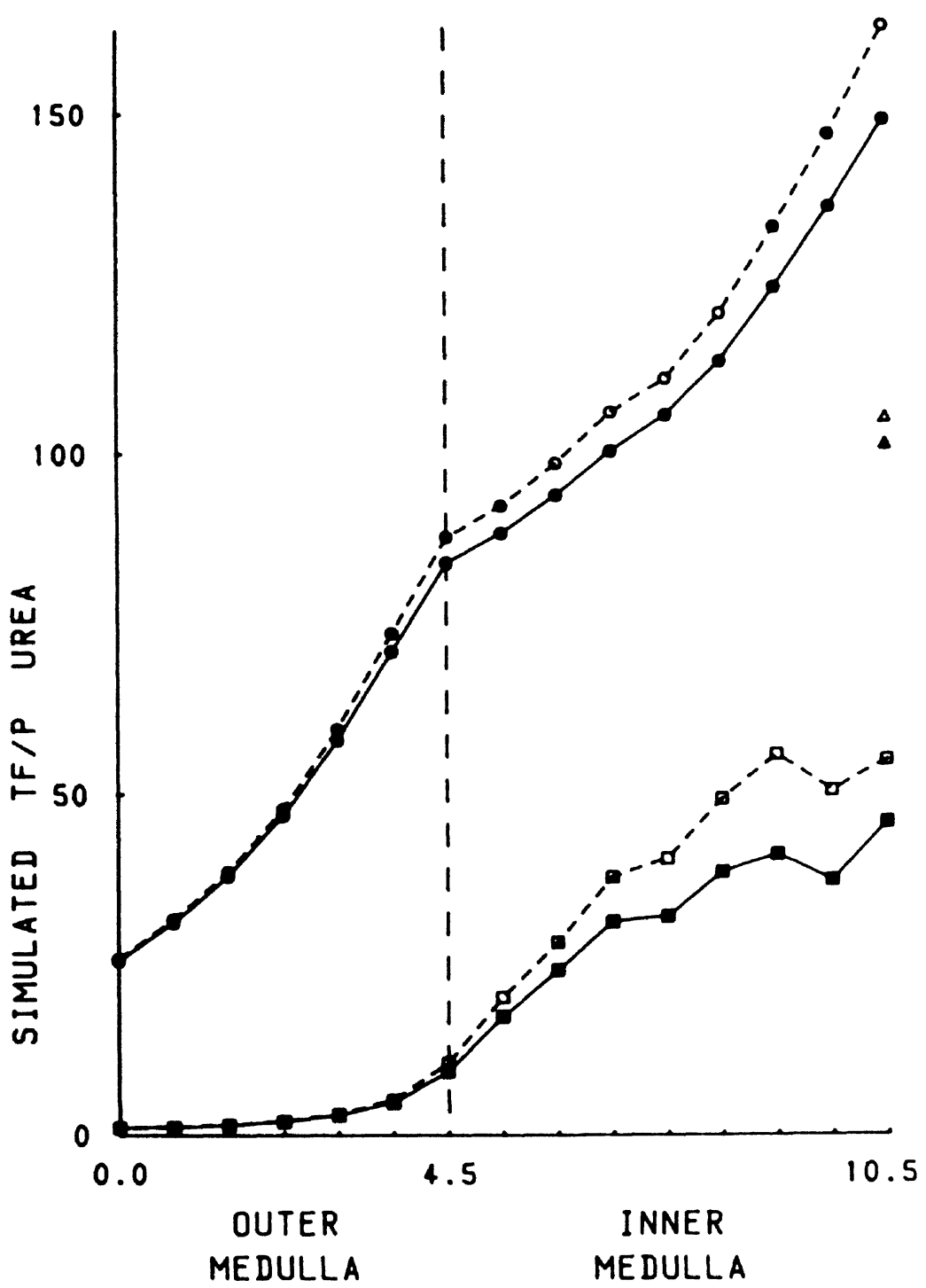

FIG. 3. Simulated urea concentration in collecting ducts (open circles, closed circles), central core (open squares, closed squares), and pelvis (open triangle, closed triangle). Open symbols, simulation $\mathrm{S}_{0}$; closed symbols, simulation $\mathrm{S}_{1}$. TF/P, tubule fluid-to-plasma. 
observations $(3,20,21)$. The functional importance of this fact for the concentrating capability has recently been studied with a highly idealized model (24).

In the long descending limbs, upper parts are distinguished. These upper parts reach from the border between outer and inner stripe $(s=1.5)$ to $s=4.5$ for groups $2-4$, to $s=6.0$ for group 5 , and to $s=8.25$ for group 6 . These architectural features are of great functional importance for the hypothesized transport cascade $(21,22)$. In Fig. 1 two short loops and three long loops are drawn. The latter reach different levels in the inner medulla. The upper parts of the long descending limbs are black. It is suggested that salt secretion occurs in these segments. These salts would be taken down to deeper levels of the inner medulla and would diffuse out of the ascending limbs. At this level, upper parts of longer long loops could take up a part of these salts to carry them down to deeper levels.

Each of the above-mentioned six groups of loops (1 group of short loops plus 5 groups of long loops) are modeled by three differential equations, $1, A$ and $B$, for the descending limbs and three differential equations, 1 , $A$ and $B$, for the ascending limbs. This especially detailed modeling of the loop system is necessary in order to allow

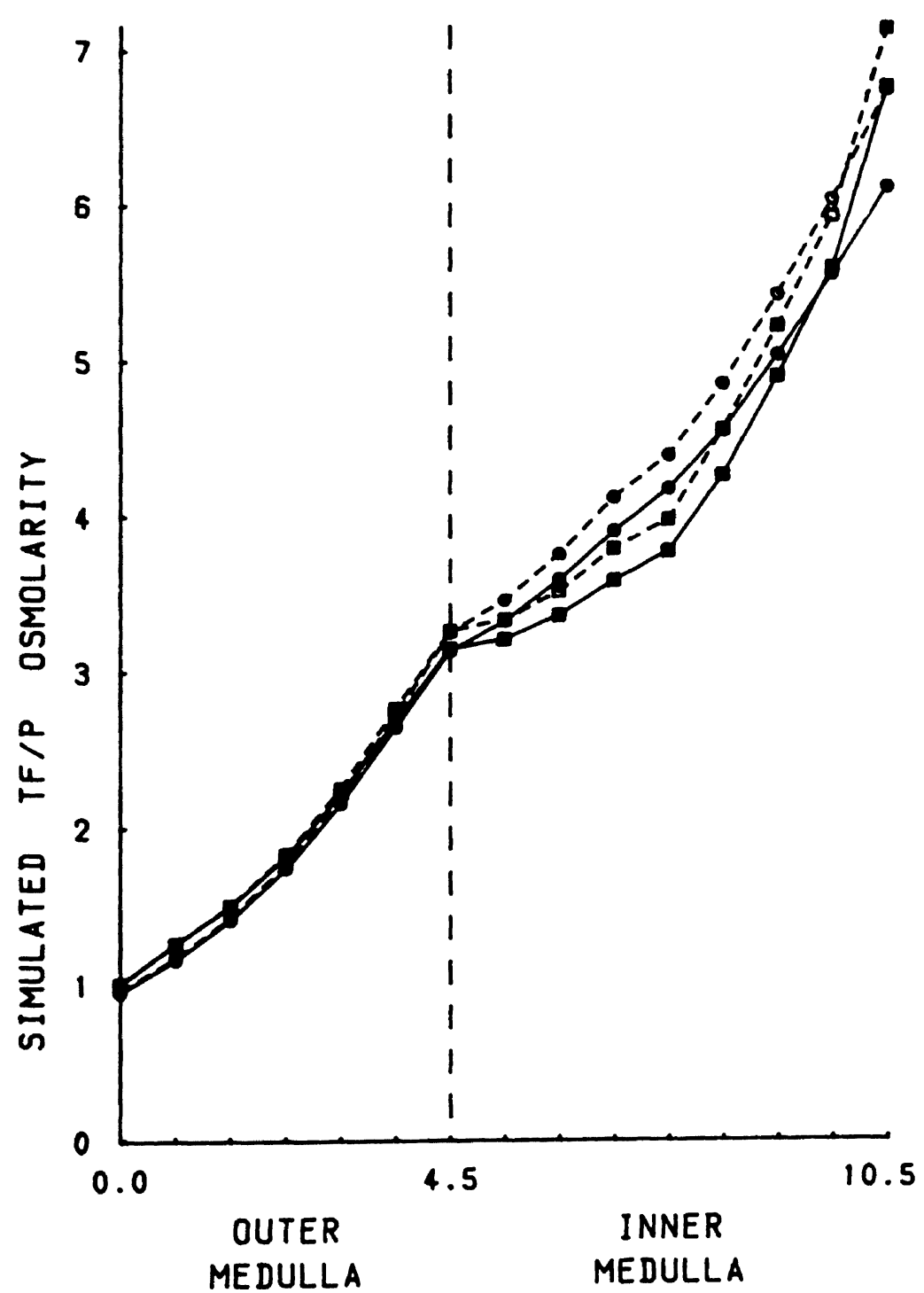

FIG. 4. Simulated total osmolarity in collecting ducts (open circles, closed circles) and central core (open squares, closed squares). Open symbols refer to simulation $S_{0}$, closed symbols refer to simulation $S_{1}$. TF/P, tubule fluid-to-plasma

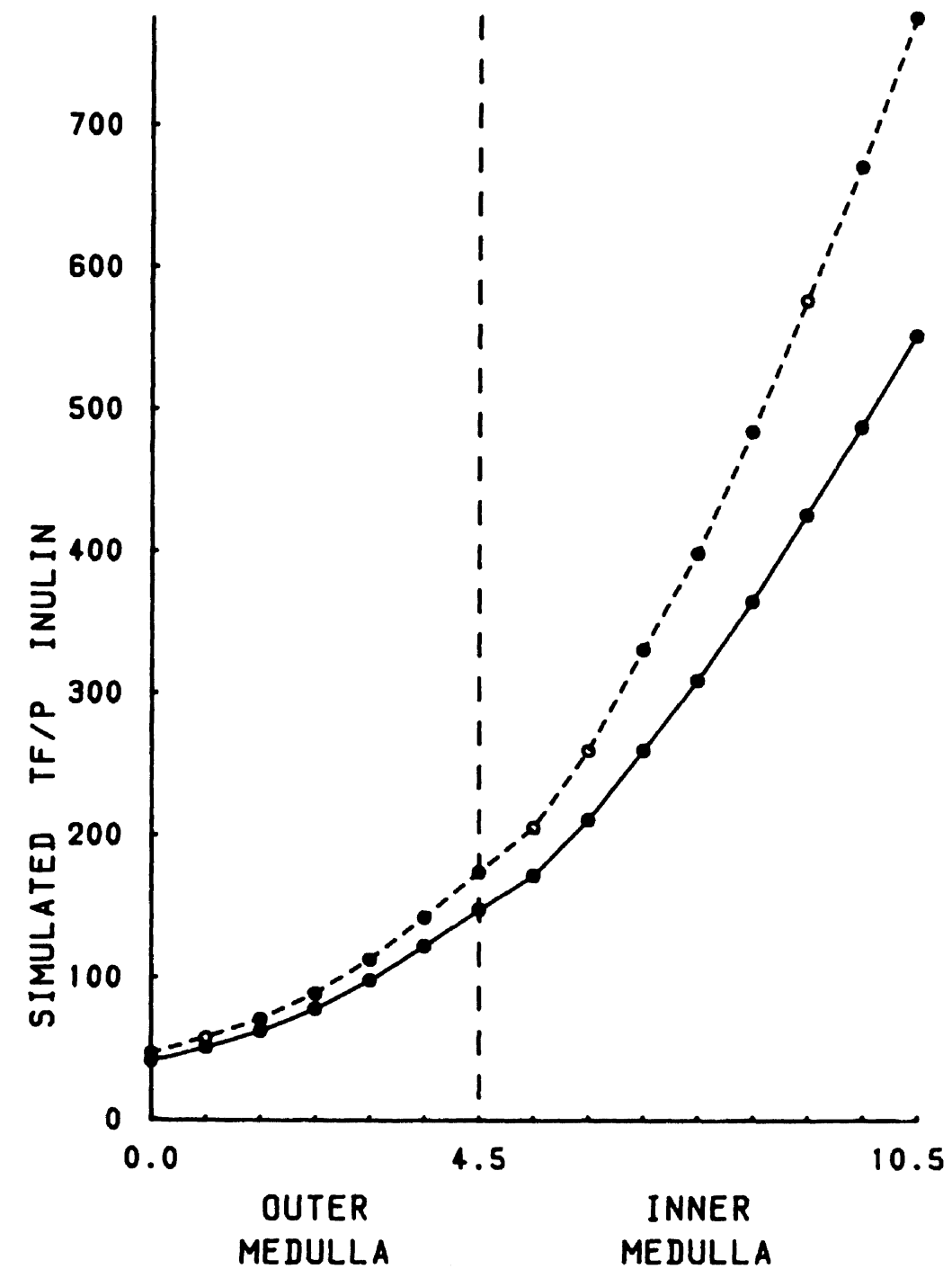

FIG. 5. Simulated tubule fluid-to-plasma (TF/P) inulin in collecting ducts for simulation $\mathrm{S}_{0}$ (open circles) and simulation $\mathrm{S}_{1}$ (closed circles).

a transport cascade in the model. All the differential equations for the medullary nephron segments and the pelvis are coupled by the differential equations for the central core. The arising multipoint boundary value problem for a system of 48 simultaneous differential equations and one unknown constant (eigenvalue problem) is given in the APPENDIX. The solution of the multipoint boundary problem on a computer makes great demands on the numerical method. A new algorithm has been developed (25) that combines features of finite element and shooting methods.

\section{RESULTS}

Tables 2-5 and Figs. 2-5 compare the computed concentrations for two simulations. In the first simulation $\left(\mathrm{S}_{0}\right)$, no active transport into the descending limbs of Henle's loops is present in the model $\left(V_{\mathrm{m}_{11}}=0.0\right.$; see $E q$. $3)$. In the second simulation $\left(S_{1}\right)$, a moderate rate of active salt transport into the upper parts of the long descending limbs is assumed $\left(V_{\mathrm{m}_{11}}=7.7 \times 10^{-6} \mathrm{mmol}\right.$. $\left.\mathrm{cm}^{-2} \cdot \mathrm{s}^{-1}, K_{\mathrm{m}_{11}}=300 \mathrm{mmol} / \mathrm{l}\right)$. In both simulations $\left(\mathrm{S}_{0}\right.$ and $S_{1}$ ), the active salt transport in the outer medullary sections of the ascending limbs is given by $V_{\mathrm{m}_{21}}=13.2 \times$ $10^{-6} \mathrm{mmol} \cdot \mathrm{cm}^{-2} \cdot \mathrm{s}^{-1}, K_{\mathrm{m}_{21}}=50 \mathrm{mmol} / \mathrm{l}$. In the distal tubule: $V_{\mathrm{m}_{31}}=12.1 \times 10^{-6} \mathrm{mmol} \cdot \mathrm{cm}^{-2} \cdot \mathrm{s}^{-1}, K_{\mathrm{m}_{31}}=100$ $\mathrm{mmol} / \mathrm{l}$. 


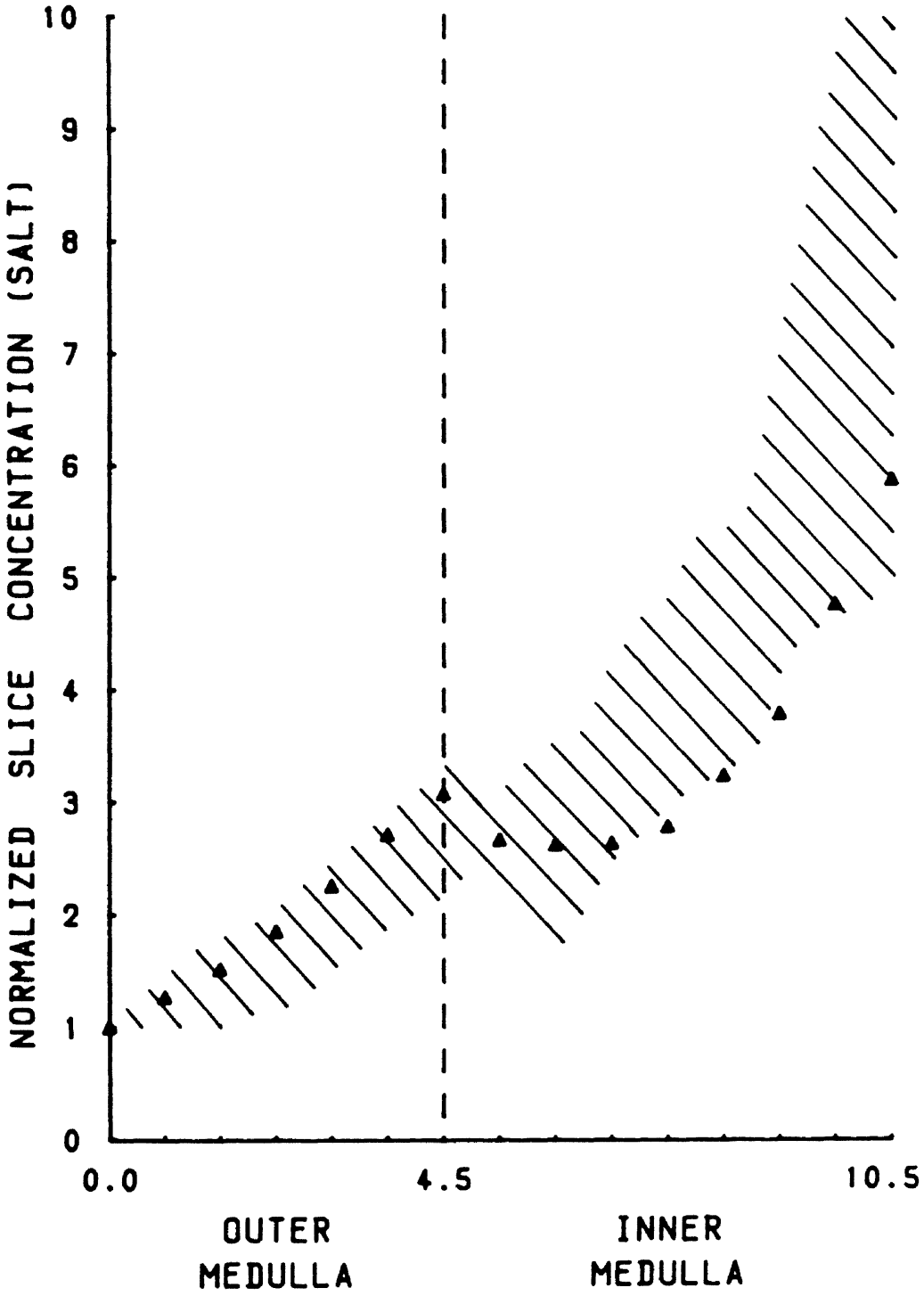

FIG. 6. Comparison of computed slice (total tissue) concentration of salt for simulation $\mathrm{S}_{1}$ (closed triangles) with measured slice concentration [hatched area (17)]. Normalization is against corticomedullary border.

The computed concentrations of salt and urea are within the range of physiological measurements. Figure 6 compares the computed slice (total tissue) concentration of salt (see Ref. 26) for simulation $S_{1}$ with the measured slice concentration [electron microprobe (17)] and shows good agreement. The concentration declines slightly over the first few millimeters of the inner medulla and rises steeply ("exponentially") in the neighborhood of the papillary tip. The corresponding computed concentration of simulation $\mathrm{S}_{0}$ is very similar (difference $\leq 4 \%)$.

Previous mathematical models of the renal concentrating mechanism were not able to produce a considerable increase of the salt concentration from the outerinner medullary junction to the papillary tip, as long as measured values were used for the parameters (14). Even the assumption of an active salt transport in the inner medullary $C D$ did not improve this situation (6). It should be noted, however, that the present model predicts a reasonable value for urine-to-plasma inulin in the $S_{1}$ case only (Table 11-5 in Ref. 13).

The computed slice concentrations for urea increase in both zones of the medulla and reach $459 \mathrm{mmol} / 1$ (simulation $\mathrm{S}_{0}$ ) and $379 \mathrm{mmol} / \mathrm{l}$ (simulation $\mathrm{S}_{1}$ ), respectively, at the papillary tip. This should be compared with a measured slice concentration of $\sim 430 \mathrm{mmol} / \mathrm{l}$ (Fig. 4 in Ref. 10).

\section{CONCLUSION}

The calculations show that an active salt transport into the upper parts of the long descending limbs would indeed produce a cascade of salt transport toward the papillary tip as supposed by $\mathrm{Kriz}(21,22)$. This is clearly demonstrated in Table 6, which compares the salt flow rates in the loops of Henle for simulations $S_{0}$ and $S_{1}$.

When active salt transport into the upper parts of the long descending limbs is present $\left(S_{1}\right)$, the salt flow rate in the loops at the papillary tip is considerably higher $(+68 \%)$ than in the absence of active transport in the descending limbs $\left(\mathrm{S}_{0}\right)$. Consequently in the $\mathrm{S}_{1}$ case, the system of Henle's loops is able to supply much more osmolarity to the remaining structures of the papillary medulla. This is demonstrated in Table 7, which compares the net efflux of total osmolarity from the loop

TABLE 6. Simulated salt flow rates in loops of Henle during absence $\left(S_{0}\right)$ and during presence $\left(S_{1}\right)$ of active salt transport into descending limbs

\begin{tabular}{|c|c|c|c|c|c|c|c|c|c|c|c|c|}
\hline \multirow{3}{*}{$s$} & \multicolumn{2}{|c|}{ Short Loop } & \multicolumn{10}{|c|}{ Long Loop of Group $j$} \\
\hline & \multirow{2}{*}{ DLH } & \multirow{2}{*}{ ALH } & \multicolumn{2}{|c|}{$\mathrm{j}=2$} & \multicolumn{2}{|c|}{$j=3$} & \multicolumn{2}{|c|}{$j=4$} & \multicolumn{2}{|c|}{$j=5$} & \multicolumn{2}{|c|}{$j=6$} \\
\hline & & & $\overline{D L H}$ & $\mathrm{ALH}$ & $\mathrm{DLH}$ & $\overline{\mathrm{ALH}}$ & $\overline{\mathrm{DLH}}$ & $\overline{\mathrm{ALH}}$ & $\overline{\text { DLH }}$ & $\overline{\mathrm{ALH}}$ & DLH & ALH \\
\hline \multirow[t]{2}{*}{0.00} & 14.0 & 2.07 & 14.0 & 1.97 & 14.0 & 1.79 & 14.0 & 1.58 & 14.0 & 1.20 & 14.0 & 0.677 \\
\hline & 14.0 & 2.20 & 14.0 & 3.06 & 14.0 & 2.78 & 14.0 & 2.46 & 14.0 & 2.17 & 14.0 & 1.32 \\
\hline \multirow[t]{2}{*}{4.50} & 13.4 & 13.4 & 13.4 & 12.0 & 13.4 & 11.1 & 13.4 & 10.2 & 13.4 & 8.42 & 13.4 & 5.28 \\
\hline & 13.4 & 13.4 & 17.0 & 15.4 & 17.0 & 14.3 & 17.0 & 13.3 & 17.0 & 12.3 & 17.0 & 8.83 \\
\hline \multirow[t]{2}{*}{5.25} & & & 13.3 & 13.3 & 13.3 & 10.6 & 13.3 & 9.59 & 13.3 & 7.85 & 13.3 & 4.89 \\
\hline & & & 16.9 & 16.9 & 16.9 & 14.0 & 16.9 & 12.7 & 18.0 & 11.7 & 18.0 & 8.33 \\
\hline \multirow[t]{2}{*}{6.00} & & & & & 13.3 & 13.3 & 13.3 & 9.54 & 13.3 & 7.61 & 13.3 & 4.73 \\
\hline & & & & & 16.9 & 16.9 & 16.9 & 12.9 & 18.9 & 11.5 & 18.9 & 8.15 \\
\hline \multirow[t]{2}{*}{6.75} & & & & & & & 13.2 & 13.2 & 13.2 & 7.51 & 13.2 & 4.64 \\
\hline & & & & & & & 16.8 & 16.8 & 18.8 & 11.7 & 19.8 & 8.21 \\
\hline \multirow{2}{*}{8.25} & & & & & & & & & 13.0 & 13.0 & 13.0 & 5.43 \\
\hline & & & & & & & & & 18.6 & 18.6 & 21.6 & 9.99 \\
\hline \multirow{2}{*}{10.5} & & & & & & & & & & & 12.5 & 12.5 \\
\hline & & & & & & & & & & & 21.0 & 21.0 \\
\hline
\end{tabular}

Values give salt flow rates in a single tubule $\left(10^{-7} \mathrm{mmol} / \mathrm{min}\right)$. In each pair, upper value refers to simulation $\mathrm{S}_{0}$, lower value refers to simulation $\mathrm{S}_{1}$. DLH, descending limb of Henle's loop; ALH, ascending limb of Henle's loop; $s$, distance into medulla from corticomedullary border. 
TABLE 7. Net efflux of total osmolarity $\left(10^{-7} \mathrm{mosmol} / \mathrm{min}\right)$ from system of Henle's loops into remaining structures in various segments of the medulla

\begin{tabular}{ccc}
\hline \hline Segment & Simulation $\mathrm{S}_{0}$ & Simulation $\mathrm{S}_{1}$ \\
\hline $0.00 \leq s \leq 10.5$ & 32,854 & 31,531 \\
$4.50 \leq s \leq 10.5$ & 1,487 & 1,565 \\
$5.25 \leq s \leq 10.5$ & 1,239 & 1,355 \\
$6.00 \leq s \leq 10.5$ & 853 & 1,022 \\
$6.75 \leq s \leq 10.5$ & 573 & 760 \\
$7.50 \leq s \leq 10.5$ & 521 & 710 \\
$8.25 \leq s \leq 10.5$ & 294 & 488 \\
$9.00 \leq s \leq 10.5$ & 231 & 378 \\
$9.75 \leq s \leq 10.5$ & 156 & 246 \\
\hline
\end{tabular}

system in various segments of the medulla for simulations $S_{0}$ and $S_{1}$. In the $S_{0}$ case, the relatively low amount of osmolarity, which is supplied to the papillary central core-CD system, can concentrate CD fluid with only a small flow rate. This concentration takes place by water extraction. In the $S_{1}$ case, however, enough osmolarity is present and CD fluid with a reasonable flow rate comes to nearly osmotic equilibrium with the surrounding interstitial space.

Thus the transport cascade of salts toward the papillary tip increases the concentrating capability of the renal countercurrent system. In the $S_{0}$ case, only $7.54 \times$ $10^{-5} \mathrm{mosmol} / \mathrm{min}$ are excreted by one collecting duct per unit time. (One collecting duct corresponds to a system of 1,536 loops.) However, in the presence of active salt transport into the upper parts of the long descending limbs $\left(\mathrm{S}_{1}\right)$ this rate increases to $9.95 \times 10^{-5} \mathrm{mosmol} / \mathrm{min}$ $(+32 \%)$.

\section{APPENDIX}

Six groups of Henle's loops of different length are present in the model. The number of loops of length $b_{j}$ is given by $\gamma_{j}\left(b_{1}\right.$ $=4.5, b_{2}=5.25, b_{3}=6.0, b_{4}=6.75, b_{5}=8.25, b_{6}=10.5 ; \gamma_{1}=$ $\left.1,024, \gamma_{2}=256, \gamma_{3}=128, \gamma_{4}=64, \gamma_{5}=32, \gamma_{6}=32\right)$. The differential equations for the loop system are $(\mathrm{j}=1, \cdots, 6)$

$$
\begin{aligned}
& \mathrm{dF}_{\mathrm{Iv}}^{\mathrm{j}} / \mathrm{d} s=-2 \pi R_{1} \times J_{1 \mathrm{v}}^{\mathrm{j}} \\
& \mathrm{dF}_{1 \mathrm{I}} / \mathrm{d} s=-2 \pi R_{1} \times \aleph_{1 \mathrm{I}} \quad \mathrm{I}=1,2 \\
& \mathrm{dF}_{2 \mathrm{v}}^{\mathrm{j}} / \mathrm{d} s=-2 \pi R_{2} \times J_{2 \mathrm{v}}^{\mathrm{j}} \\
& \mathrm{dF}_{2 \mathrm{I}} / \mathrm{d} s=-2 \pi R_{2} \times J_{\mathrm{2I}} \quad \mathrm{I}=1,2
\end{aligned}
$$

The transmural fluxes $J_{i v}^{\mathrm{i}}$ and $J_{i 1}^{\mathrm{i}}$ are defined by Eqs. 2, $A$ and $B$ and 3. The index $\mathrm{j}$ refers to the number of the group.

Each of the following nephron segments, DT and CD, are modeled by a composite structure (see Ref. 26,28 ). Let $\mathscr{F}_{3 v}, \mathscr{F}_{31}$ and $\mathscr{F}_{4 v}, \mathscr{F}_{41}$ denote the flows in the composite DT and the composite $\mathrm{CD}$, respectively. They represent the sum of the flows in the single tubules, and the concentration of the fluid within the composite structure reflects the mixture of the fluids in the single tubules.

The 1,536 distal tubules are modeled by

$$
\begin{aligned}
\mathrm{d} \mathscr{F}_{3 \mathrm{v}} / \mathrm{ds}=-2 \pi R_{3} \times 1,536 \times J_{3 \mathrm{v}} \\
\mathrm{d} \mathscr{F}_{3 \mathrm{l}} / \mathrm{ds}=-2 \pi R_{3} \times 1,536 \times J_{3 \mathrm{I}} \quad \mathrm{I}=1,2
\end{aligned}
$$

During passage through the DT, the fluid interacts with the cortical interstitium, where the solute concentrations are assumed to be the same as in the arterial plasma $\left(C_{p_{1}}=140\right.$ $\left.\mathrm{mmol} / \mathrm{l}, \mathrm{C}_{\mathrm{p}_{2}}=9 \mathrm{mmol} / \mathrm{l}\right)$. Hence

$$
\begin{aligned}
J_{3 \mathrm{v}}= & \mathrm{L}_{\mathrm{p}_{3}} \times\left[1.82 \sigma_{31}\left(\mathrm{C}_{\mathrm{p}_{1}}-\mathrm{C}_{31}\right)+\sigma_{32}\left(\mathrm{C}_{\mathrm{p}_{2}}-\mathrm{C}_{32}\right)\right] \\
J_{3 \mathrm{I}}= & \mathrm{P}_{3 \mathrm{I}} \times\left(\mathrm{C}_{3 \mathrm{I}}-\mathrm{C}_{\mathrm{p}_{\mathrm{I}}}\right)+\left(1-\sigma_{3 \mathrm{I}}\right) \times J_{3 \mathrm{v}} \\
& \times\left(\mathrm{C}_{3 \mathrm{I}}+\mathrm{C}_{\mathrm{p}_{\mathrm{I}}}\right) / 2+\mathrm{T}_{3 \mathrm{I}}
\end{aligned}
$$

The differential equations for the $\mathrm{CD}$ system are

$$
\begin{aligned}
& \mathrm{d} \mathscr{F}_{4 \mathrm{v}} / \mathrm{ds}=-2 \pi R_{4} \times \mathrm{NCD}(\mathrm{s}) \times J_{4 \mathrm{v}} \\
& \mathrm{d} \mathscr{F}_{4 \mathrm{I}} / \mathrm{ds}=-2 \pi R_{4} \times \mathrm{NCD}(\mathrm{s}) \times J_{4 \mathrm{I}} \quad \mathrm{I}=1,2
\end{aligned}
$$

Here, NCD(s) is the number of collecting ducts present at depth $\mathbf{s}$ of the medulla (see text).

Pelvic reflux of urea across the side wall of the papillary central core (PRUS) (26) is determined by

$$
\text { PRUS }=\int_{8.25}^{10.5} \mathrm{CF}_{5}(s) \times \mathrm{J}_{52}(s) \dot{\mathrm{d} s}
$$

where $\mathrm{CF}_{5}(s)$ is the circumference of the total medulla multiplied by the normalizing factor 1,536/(total number of loops of a kidney). Equation $A 9^{\prime}$ allows a trivial transformation to

$$
\operatorname{prus}^{\prime}(\mathrm{s})=\mathrm{CF}_{5}(s) \times \mathrm{J}_{52}(s)
$$

prus $(8.25)=0$. Then, $\operatorname{PRUS}=\operatorname{prus}(10.5)$

The differential equations $A 1-A 4, A 7$, and $A 8$ for the tubules in the medulla and for the pelvis (A9) are coupled by the differential equations for the central core flows, which are derived from the requirement of mass balance

$$
\begin{aligned}
& \mathrm{dF}_{6 \mathrm{v}} / \mathrm{d} s=-\sum_{\mathrm{j}=\mathrm{j}_{\mathrm{a}}}^{6} \gamma_{\mathrm{j}} \times\left(\mathrm{dF} \mathrm{i}_{\mathrm{v}} / \mathrm{d} s+\mathrm{dFi}_{\mathrm{vv}} / \mathrm{d} s\right) \\
& -\mathrm{d} \mathscr{\mathscr { F } _ { \mathrm { uv } }} / \mathrm{d} s \\
& \mathrm{dF}_{61} / \mathrm{d} s=-\sum_{j=j_{\mathrm{d}}}^{6} \gamma_{\mathrm{j}} \times\left(\mathrm{dF}_{11} / \mathrm{d} s+\mathrm{dF}_{\mathrm{i}_{1}} / \mathrm{d} s\right) \\
& -\mathrm{d} \mathscr{F}_{41} / \mathrm{d} s \\
& \mathrm{dF}_{62} / \mathrm{d} s=-\sum_{j=j_{6}}^{6} \gamma_{\mathrm{j}} \times\left(\mathrm{dF}_{12}^{\mathrm{j}_{2}} / \mathrm{d} s+\mathrm{dF}_{22}^{\mathrm{j}_{2}} / \mathrm{d} s\right) \\
& -\mathrm{d} \mathscr{F}_{42} / \mathrm{d} s+\mathrm{CF}_{5}(s) \times \mathrm{J}_{52}
\end{aligned}
$$

where $J_{52} \equiv 0$ for $0.0 \leq s \leq 8.25$ and $\mathrm{j}_{\mathrm{a}}=\nu$ for $b_{\nu-1}<s \leq b_{\nu}$

In the central core, the model allows solute movement along the medullary axis by both convection and diffusion

$$
\mathrm{F}_{6 \mathrm{I}}=\mathrm{F}_{6 \mathrm{v}} \times \mathrm{C}_{6 \mathrm{I}}-D_{\mathrm{I}} \times A \mathrm{C}(s) \times \mathrm{dC}_{6 \mathrm{I}} / \mathrm{d} s \quad \mathrm{I}=1,2
$$

where $D_{\mathrm{I}}$ denotes the diffusion coefficient of solute I and $A \mathrm{C}(s)$ the cross-sectional area of the central core.

Altogether, Eqs. A1-A13 define a system of 48 simultaneous differential equations and one unknown constant $\mathrm{C}_{52}$ (urea concentration in the pelvis). Consequently, 49 boundary conditions are necessary. Boundary conditions for the tubules $(j=$ $1, \cdots, 6)$

$F_{1 v}^{j}(0)=Q_{0}(=$ volume flow rate into a single DLH

$$
=10 \mathrm{nl} / \mathrm{min} \text { ) }
$$

$$
\begin{aligned}
& \mathrm{F}_{11}^{\mathrm{j}}(0)=\mathrm{Q}_{0} \times \mathrm{C}_{\mathrm{p}_{1}} \quad \mathrm{~F}_{12}^{\mathrm{j}}(0)=\mathbf{Q}_{0} \times 2 \mathrm{C}_{\mathrm{p}_{2}} \\
& F_{i_{v}}\left(b_{j}\right)=-F_{i_{v}}\left(b_{j}\right) \quad F_{i_{I}}\left(b_{j}\right)=-F_{i I}\left(b_{j}\right) \quad I=1,2 \\
& \mathscr{F} \mathscr{F}_{3 v}(0)=-\sum_{j=1}^{6} \gamma_{j} \times F_{2 v}^{j_{v}}(0) \quad \mathscr{F _ { 3 I }}(0)=-\sum_{j=1}^{6} \gamma_{j} \times F_{2 I}^{j_{I}}(0) \\
& \mathrm{I}=1,2 \\
& \mathscr{F}_{4 v}(0)=\mathscr{F}_{3 \mathrm{v}}\left(L_{\mathrm{DT}}\right) \quad\left(L_{\mathrm{DT}}=\text { length of DT }\right) \\
& \mathscr{F}_{4 I}(0)=\mathscr{F}_{3 \mathrm{I}}\left(L_{\mathrm{DT}}\right) \quad \mathrm{I}=1,2
\end{aligned}
$$


Boundary conditions for the central core

$$
\begin{aligned}
\mathrm{C}_{61}(0) & =\mathrm{C}_{\mathrm{p}_{\mathrm{I}}} \quad \mathrm{I}=1,2 \\
\mathrm{~F}_{6 \mathrm{v}}(10.5) & =\mathrm{F}_{61}(10.5)=0 \quad \mathrm{~F}_{62}(10.5)=-\mathrm{PRUC}
\end{aligned}
$$

where PRUC denotes pelvic urea reflux across the cover wall of the papillary central core (26), i.e., $\mathrm{PRUC}=A \mathrm{C}(10.5) \times \mathrm{P}_{52}$ $\times\left[\mathrm{C}_{52}-\mathrm{C}_{62}(10.5)\right]$

Boundary conditions for the pelvis

$$
\begin{aligned}
\operatorname{prus}(8.25) & =0 \\
\mathscr{F}_{42}(10.5) & =\mathscr{F}_{4 \mathrm{v}}(10.5) \times \mathrm{C}_{52}+\text { PRUS } \\
& + \text { PRUC } \quad \text { (mass balance) }
\end{aligned}
$$

\section{Geometric Parameters}

$L_{\mathrm{DT}}=2.625 \mathrm{~mm}$. The radii of the individual tubules are $\mathrm{DLH}$ $8 \mu \mathrm{m}$, ALH $10 \mu \mathrm{m}$, DT linear transition from 10 to $8 \mu \mathrm{m}$, $\mathrm{CD}$ (outer medulla) $12 \mu \mathrm{m}, \mathrm{CD}$ (inner medulla) $24 \mu \mathrm{m}$ (15). For references and for $A C$ (s) see (26).

The author thanks Professor M. Horster (München) and Professor W. Kriz (Heidelberg) for their valuable suggestions.

A preliminary report of this study has been presented in abstract form (Pfluegers Arch. 405: R118, 1985).

Received 24 April 1986; accepted in final form 8 January 1987.

\section{REFERENCES}

1. Abramow, M., AND L. OrCI. On the "tightness" of the rabbit descending limb of the loop of Henle-physiological and morphological evidence. Int. J. Biochem. 12: 23-27, 1980.

2. Al-Zahid, G., J. A. Schafer, S. L. Troutman, and T. E. ANDREOLI. Effect of antidiuretic hormone on water and solute permeation, and the activation energies for these processes, in mammalian cortical collecting tubules. Evidence for parallel ADHsensitive pathways for water and solute diffusion in luminal plasma membranes. J. Membr. Biol. 31: 103-129, 1977.

3. BECKER, B. Quantitative Beschreibung der Innenzone der Rattenniere (MD dissertation). Münster: Univ. of Münster, 1978.

4. Burg, M., S. Helman, J. Grantham, and J. Orloff. Effect of vasopressin on the permeability of isolated rabbit cortical collecting tubules to urea, acetamide, and thiourea. In: Urea and the Kidney, edited by B. Schmidt-Nielsen and D. W. S. Kerr. Amsterdam: Excerpta Medica, 1970, p. 193-199.

5. CAPEK, K., G. FudA, G. RUMrich, and K. J. UllRich. Harnstoffpermeabilität der corticalen Tubulusabschnitte von Ratten in Antidiurese und Wasserdiurese. Pfluegers Arch. 290: 237-249, 1966.

6. Chandhoke, P. S., G. M. SAIDEL, AND M. A. KNEPPER. Role of inner medullary collecting duct $\mathrm{NaCl}$ transport in urinary concentration. Am. J. Physiol. 249 (Renal Fluid Electrolyte Physiol. 18): F688-F697, 1985.

7. ERNST, S. A., AND J. H. Schreiber. Ultrastructural localization of $\mathrm{Na}^{+}, \mathrm{K}^{+}$-ATPase in rat and rabbit kidney medulla. J. Cell Biol. 91: 803-813, 1981.

8. GILG, A. Simulationen an einem zeitabhängigen Modell des Gegenstromsystems der Niere. In: Simulationstechnik, edited by D. F. P. Möller. Berlin: Springer, 1985, vol. 109, 355-365.

9. GotTschalK, C. W., AND M. Mylle. Micropuncture study of the mammalian urinary concentrating mechanism: evidence for the countercurrent hypothesis. Am. J. Physiol. 196: 927-936, 1959.

10. GUNTHER, R. A., AND L. RABINOWITZ. Urea and renal concentrating ability in the rabbit. Kidney Int. 17: 205-222, 1980.

11. Horster, M. F., A. GILG, AND P. LoRY. Determinants of axial osmotic gradients in the differentiating countercurrent system.
Am. J. Physiol. 246 (Renal Fluid Electrolyte Physiol. 15): F124F132, 1984.

12. ImaI, M., AND J. P. KoKKo. Sodium chloride, urea and water transport in the thin ascending limb of Henle: generation of osmotic gradients by passive diffusion of solutes. J. Clin. Invest. 53: 393-402, 1974.

13. JAMison, R. L. Urine concentration and dilution. In: The Kidney, edited by B. M. Brenner and F. C. Rector, Jr. Philadelphia, PA: Saunders, 1981, vol. 1, p. 495-550.

14. JAmison, R. L., AND C. R. Robertson. Recent formulations of the urinary concentrating mechanism: a status report. Kidney Int. 16: 537-545, 1979.

15. KAINER, R. A geometric model of the rat kidney. Anat. Embryol. 147: 91-109, 1975 .

16. Katchalsky, A., AND P. F. CURRan. Nonequilibrium Thermodynamics in Biophysics. Cambridge, MA: Harvard Univ. Press, 1967.

17. Koepsell, H., W. A. P. Nicholson, W. KRIZ, AND H. J. HÖHLING. Measurements of exponential gradients of sodium and chlorine in the rat kidney medulla using the electron microprobe. Pfluegers Arch. 350: 167-184, 1974.

18. KокKо, J. P. Sodium chloride and water transport in the descending limb of Henle. J. Clin. Invest. 49: 1838-1846, 1970.

19. Кокко, J. P. Urea transport in the proximal tubule and the descending limb of Henle. J. Clin. Invest. 51: 1999-2008, 1972.

20. KRIZ, W. Structural organization of the renal medulla: comparative and functional aspects. Am. J. Physiol. 241 (Regulatory Integrative Comp. Physiol. 10): R3-R16, 1981.

21. KRIZ, W. Structural organization of the renal medullary counterflow system. Federation Proc. 42: 2379-2385, 1983.

22. KRIZ, W. Structure and function of the renal medulla. In: Paediatric Nephrology, edited by J. Brodehl and J. H. Ehrich. New York: Springer, 1984, p. 3-10.

23. KRIz, W., A. SChILleR, AND R. TAUGNER. Freeze-fracture studies on the thin limbs of Henle's loop in Psammomys obesus. Am. J. Anat. 162: 23-33, 1981

24. Layton, H. E. Distribution of Henle's loops may enhance urine concentrating capability. Biophys. J. 49: 1033-1040, 1986.

25. LORY, P. Ein Semi-Kollokationsverfahren zur numerischen Lösung von Nierenmodellen. München: Technische Universität München, 1985. (Tech. Rep. TUM-M8501)

26. LORY, P., A. GILG, AND M. HoRSTER. Renal countercurrent system: role of collecting duct convergence and pelvic urea predicted from a mathematical model. J. Math. Biol. 16: 281-304, 1983.

27. MEJiA, R., AND J. L. STEPhenson. Numerical solution of multinephron kidney equations. J. Comput. Physics 32: 235-246, 1979.

28. Moore, L. C., AND D. J. MarSh. How descending limb of Henle's loop permeability affects hypertonic urine formation. Am. J. Physiol. 239 (Renal Fluid Electrolyte Physiol. 8): F57-F71, 1980.

29. Morgan, T., AND R. W. Berliner. Permeability of the loop of Henle, vasa recta, and collecting duct to water, urea, and sodium. Am. J. Physiol. 215: 108-115, 1968.

30. RoCHA, A., AND J. P. KoKKo. Sodium chloride and water transport in the medullary thick ascending limb of Henle. J. Clin. Invest. 52: $612-623,1973$.

31. Rocha, A., AND J. P. KoкKo. Permeability of medullary nephron segments to urea and water: effect of vasopressin. Kidney Int. 6: 379-387, 1974.

32. Schafer, J. A., AND T. E. ANDreoli. The effect of antidiuretic hormone on solute flows in mammalian collecting tubules. J. Clin. Invest. 51: 1279-1286, 1972.

33. Stephenson, J. L. Concentration of urine in a central core model of the renal counterflow system. Kidney Int. 2: 85-94, 1972.

34. Stephenson, J. L., R. P. Tewarson, AND R. MEJIA. Quantitative analysis of mass and energy balance in non-ideal models of the renal counterflow system. Proc. Natl. Acad. Sci. USA 71: 16181622,1974

35. Ullrich, K. J., G. RUmRich, AND C. A. Baldamus. Mode of urea transport across the mammalian nephron. In: Urea and the Kidney, edited by B. Schmidt-Nielsen and D. W. S. Kerr. Amsterdam: Excerpta Medica, 1970, p. 175-185. 